\title{
A mini-review of quality of life as an outcome in prostate cancer trials: patient- centered approaches are needed to propose appropriate treatments on behalf of patients
}

\author{
Yohann Foucher ${ }^{1,2^{*}}$ (D), Marine Lorent ${ }^{1}$, Philippe Tessier ${ }^{1,2}$, Stéphane Supiot ${ }^{3}$, Véronique Sébille ${ }^{1,2}$
} and Etienne Dantan'

\begin{abstract}
Background: Patients with prostate cancer (PC) may be ready to make trade-offs between their quantity and their quality of life. For instance, elderly patients may prefer the absence of treatment if it is associated with a low-risk of disease progression, compared to treatments aiming at preventing disease progression but with a substantial deterioration of their Health-Related Quality of Life (HRQoL). Therefore, it seems relevant to compare the treatments by considering both survival and HRQoL. In this mini-review, the aim was to question whether the potential trade-offs between survival and HRQoL are considered in high impact factor journals.

Methods: The study was conducted from the PubMed database for recent papers published between May 01, 2013, and May 01, 2015. We also restricted our search to nine medical journals with 2013 impact factor > 15.

Results: Among the 30 selected studies, only six collected individual HRQoL as a secondary endpoint by using the Functional Assessment of Cancer Therapy-Prostate (FACT-P) questionnaire. In four studies, the time to HRQoL change was analyzed, but its definitions varied. In two studies, the mean changes in HRQoL between the baseline and the 12- or 16-week follow-up were analyzed. None of the six studies reported in a single endpoint both the quantity and the quality of life.

Conclusions: Our mini-review, which only focused on recent publications in journals with high-impact, suggests moving PC clinical research towards patient-centered outcomes-based studies. This may help physicians to propose the most appropriate treatment on behalf of patients. We recommend the use of indicators such as Quality-Adjusted Life-Years (QALYS) as principal endpoint in future clinical trials.
\end{abstract}

Keywords: Prostate cancer, Review of clinical trials, Patient-centered outcomes, Quality of life

\footnotetext{
* Correspondence: Yohann.Foucher@univ-nantes.fr

${ }^{1}$ SPHERE (MethodS for Patients-centered outcomes and HEalth Research),

INSERM UMR 1246, Nantes University, IRS2 - 22 boulevard Bénoni Goullin,

44200 Nantes, France

${ }^{2} \mathrm{CHU}$ Nantes University Hospital, Nantes, France

Full list of author information is available at the end of the article
}

(c) The Author(s). 2018 Open Access This article is distributed under the terms of the Creative Commons Attribution 4.0 International License (http://creativecommons.org/licenses/by/4.0/), which permits unrestricted use, distribution, and reproduction in any medium, provided you give appropriate credit to the original author(s) and the source, provide a link to the Creative Commons license, and indicate if changes were made. The Creative Commons Public Domain Dedication waiver (http://creativecommons.org/publicdomain/zero/1.0/) applies to the data made available in this article, unless otherwise stated. 


\section{Background}

In Europe, Prostate Cancer (PC) is the second most frequent cancer in men with an incidence of 9.55 per 1000 person-years when an invitation to screening is performed and 6.23 per 1000 person-years otherwise [1]. Early diagnosis improved by PSA testing has recently allowed a better estimation of its incidence [2]. Over the last decades, many progresses have been done in the treatment of patients with $\mathrm{PC}$, partially explained by the improvement of the prediction of the disease progression based on scoring systems [3, 4]. The objectives of assessing PC patients' risk level of future adverse health events is i) to avoid over-treatment of patients at lowrisk of recurrence or death related to $\mathrm{PC}$, and ii) to avoid under-treatment of high-risk patients.

Although guidelines are available for such stratified medical decision making $[5,6]$, some questions remain unresolved. One of the main issues to address concerns the trade-offs between the benefits and the costs of possible treatment options in terms of both survival and health-related quality of life (HRQoL). Several studies have shown that $\mathrm{PC}$ patients are ready to make trade-offs between their quantity and their quality of life [7-10], especially when providing balanced information of different treatment options [11]. For instance, elderly patients may never experience disease progression to metastatic stage during their remaining lifetime [12], while treatments aiming at preventing disease progression can substantially deteriorate their HRQoL [13]. Younger men may also prefer interventions that preserve their HRQoL, but at the potential cost of reducing the disease progression-free survival. In a patient-centered medical decision making perspective, the treatments should therefore be compared against each other by weighting their benefits and costs in terms of both survival and HRQoL.

In this context, we proposed a mini-review. This type of study provides a focused review of the literature, the main objective being to raise questions or to suggest new hypotheses for research. We aimed to question whether the trade-offs between survival and HRQoL are considered in high-impact factor journals and to suggest recommendations for future studies based on patient-centered endpoints.

\section{Methods}

\section{Literature search strategy}

A literature search was conducted from the PubMed database for recent papers published between May 01, 2013, and May 01, 2015. In order to obtain a picture of the main trends in the medical literature, we focused on nine prominent journals in oncology or general medicine (impact factor $\geq 15$ in 2013). We indicated "prostatic neoplasms » as Medical
Subject Headings (MeSH) terms and " randomized controlled trial » as publication type. The research equation used in PubMed is presented in Additional file 1. The PRISMA-P (Preferred Reporting Items for Systematic review and Meta-Analysis Protocols) checklist is also provided in the Additional file 2.

\section{Data extraction}

All papers resulting from this search were independently double-blinded reviewed (Y Foucher, $M$ Lorent, or E Dantan). The first task was to exclude papers associated with non-randomized controlled trials, non-original works, without patients' followup, or non-comparative analyses. The second task was to collect the following characteristics from the selected papers: the study design, the patients' inclusion criteria, the patients' maximum follow-up duration, the compared treatments, the sample size in each arm, the endpoints, the statistical methods used, the reference to the results of an additional paper and the financial support. If any disagreements between reviewers occurred, they were solved by discussions. We used Zotero to manage the records.

\section{Results \\ Retained studies}

The PubMed request allowed identifying 42 papers (Fig. 1). Because we only considered randomized clinical trials comparing at least two interventions, 12 publications were excluded: six re-analyses of clinical trials evaluating the prognostic capacities of markers or models [14-19]; one study related to body mass index (no comparison of treatments) [20]; one study without patients' follow-up [21]; one paper without original results [22]; one case-cohort study [23]; one study without control group [24]; and one diagnostic study [25]. Finally, 30 papers [1, 26-54] were retained and are described in Table 1 . As detailed in the last column entitled "other results", two papers referred to the trial NCT00887198 [27, 47] and three papers referred to the trial NCT00699751 [37, 42, 48].

\section{Collected endpoints}

Among the 30 papers, only 8 [26-28, 33, 35, 42, 43, 53] were partially based on the collection of Patient Reported Outcomes (PRO). Their median follow-up was 38 months (range from 12 to 52 months) versus 54 months (range from 3 months to 18 years) in the 22 remaining papers. Among the 8 retained papers, six [27, 28, 33, 35, 42, 53] compared the treatments consequences on the patient HRQoL collecting the Functional Assessment of Cancer Therapy-Prostate (FACT-P) questionnaire [55, 56]. The FACT-P is an internationally validated questionnaire specifically designed to assess the HRQoL of men with PC. It is derived from the FACT-General (FACT-G) 


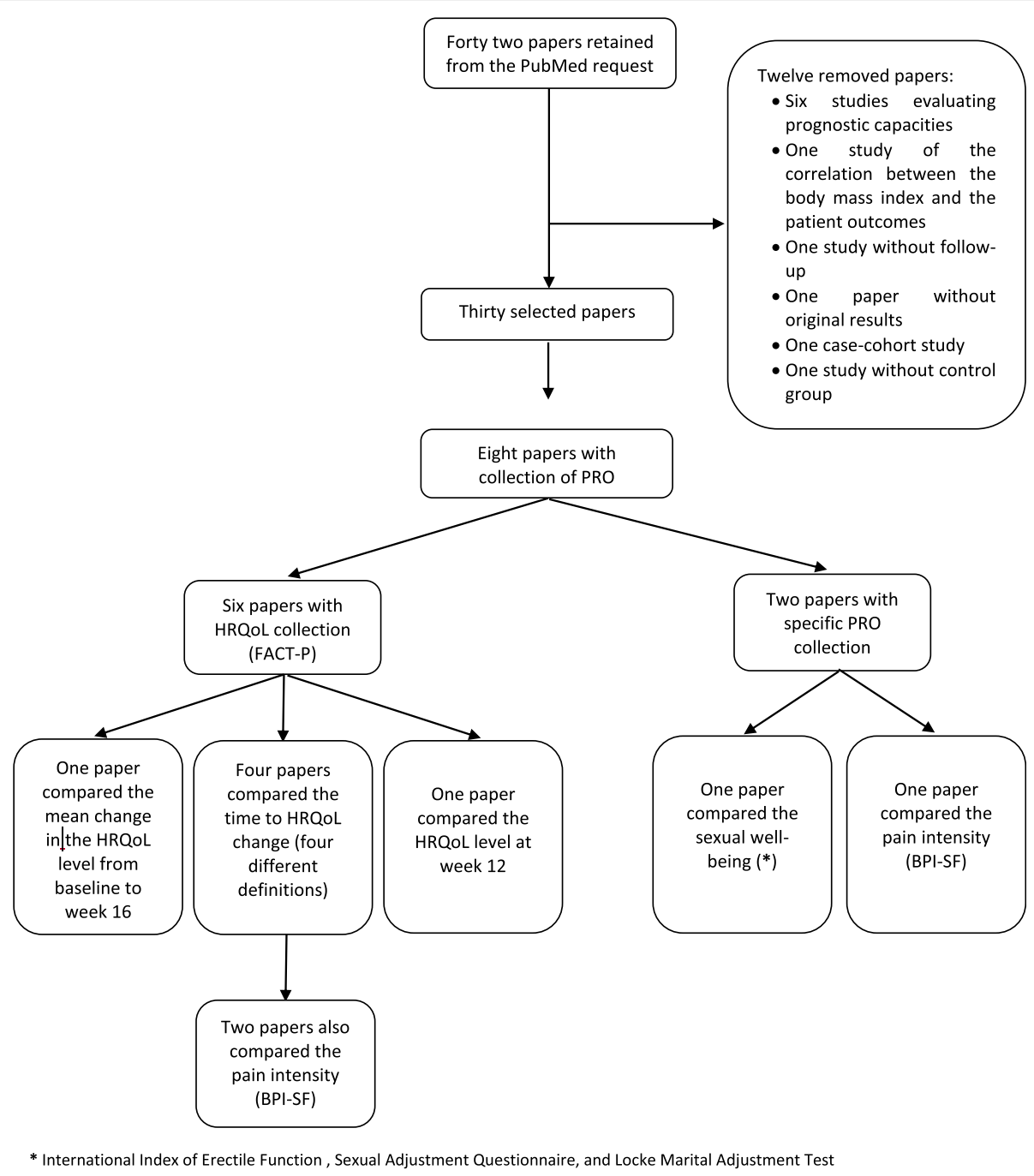

Fig. 1 Flow diagram of the literature search strategy and the used patient reported outcomes

questionnaire with an additional subscale of 12 items specific to PC (the Prostate Cancer Subscale, PCS). The FACT-G is a 27 items self-report questionnaire measuring general HRQOL in cancer patients (regardless of the tumor type). High FACT-P total score indicates better HRQoL. Note that some indexes are also derived from the FACT-P: the Trial Outcome Index (TOI) based on the physical and functional well-being subscales of the FACT-G and the PCS, and the FACT Advanced Prostate Symptom Index (FAPSI) including eight items from the FACT-P. The two remaining papers compared the interventions in terms of specific PRO: Araujo et al. [26] assessed the patients' pain with the Short Form of the Brief Pain Inventory (BPI-SF) [57, 58], while Pisansky et al. [43] focused on sexual disorders with the International Index of Erectile Function [59], the Sexual Adjustment Questionnaire [60], and the Locke Marital Adjustment Test [61]. Among the six papers using the FACT-P questionnaire, two papers also employed the BPI-SF questionnaire [27, 35]. Note that only the study proposed by Basch et al. [27] presented a PRO measure (the pain intensity) as primary endpoint. Nevertheless, this paper referred to the same randomized clinical trial initially reported by Ryan et al. [47], which was designed (in particular the sample size determination) by using co-primary endpoints: the radiographic progression-free survival and the overall survival. Therefore, among the 27 trials included in the review, none was specifically designed to analyze the consequences of interventions in terms of HRQoL as a primary endpoint.

\section{Statistical analyzes used to compare consequences in terms of HRQoL}

Among the eight papers including some results related to PRO [26-28, 33, 35, 42, 43, 53], two main strategies were adopted: i) the analysis of the time to HRQoL 


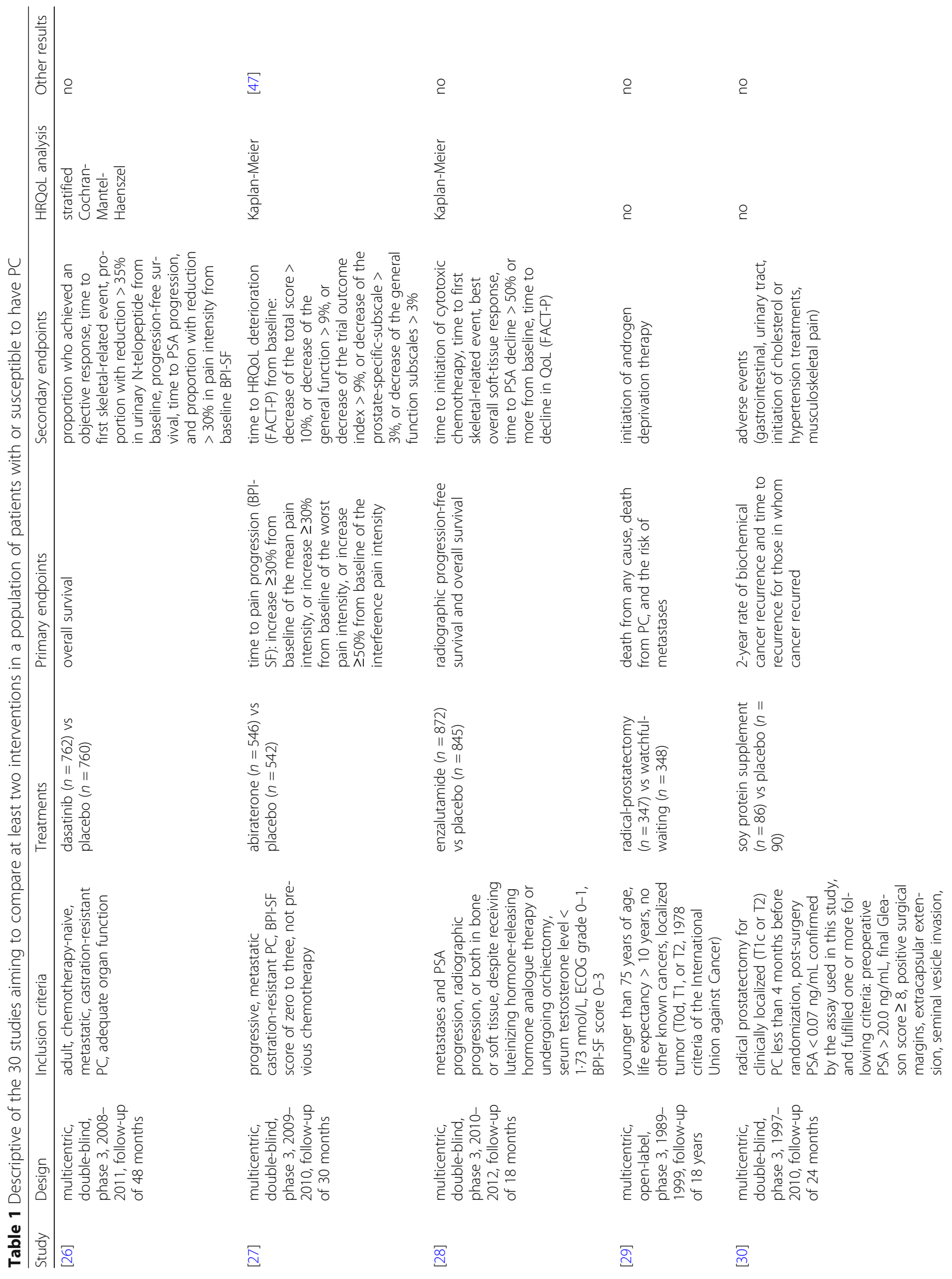




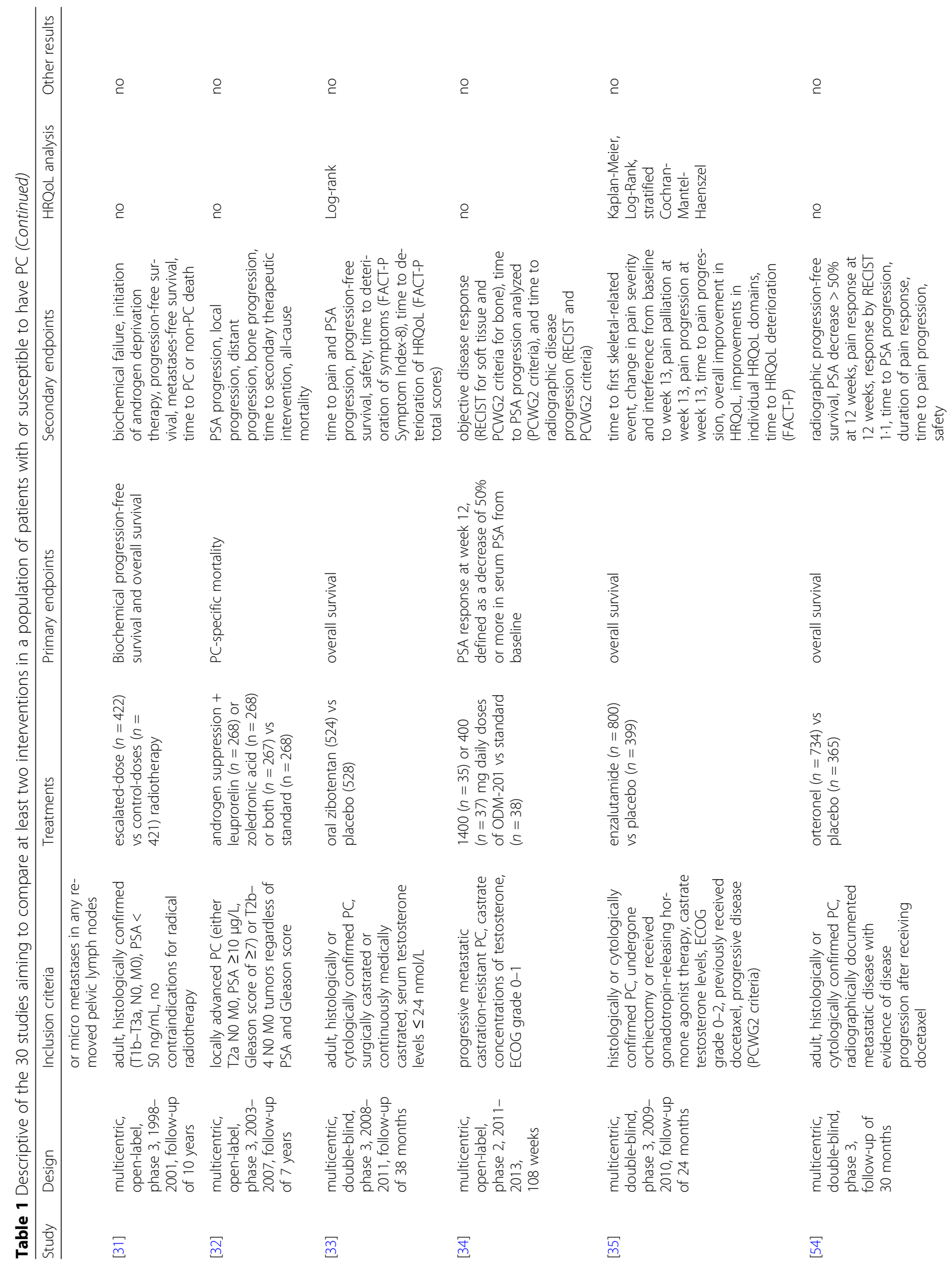




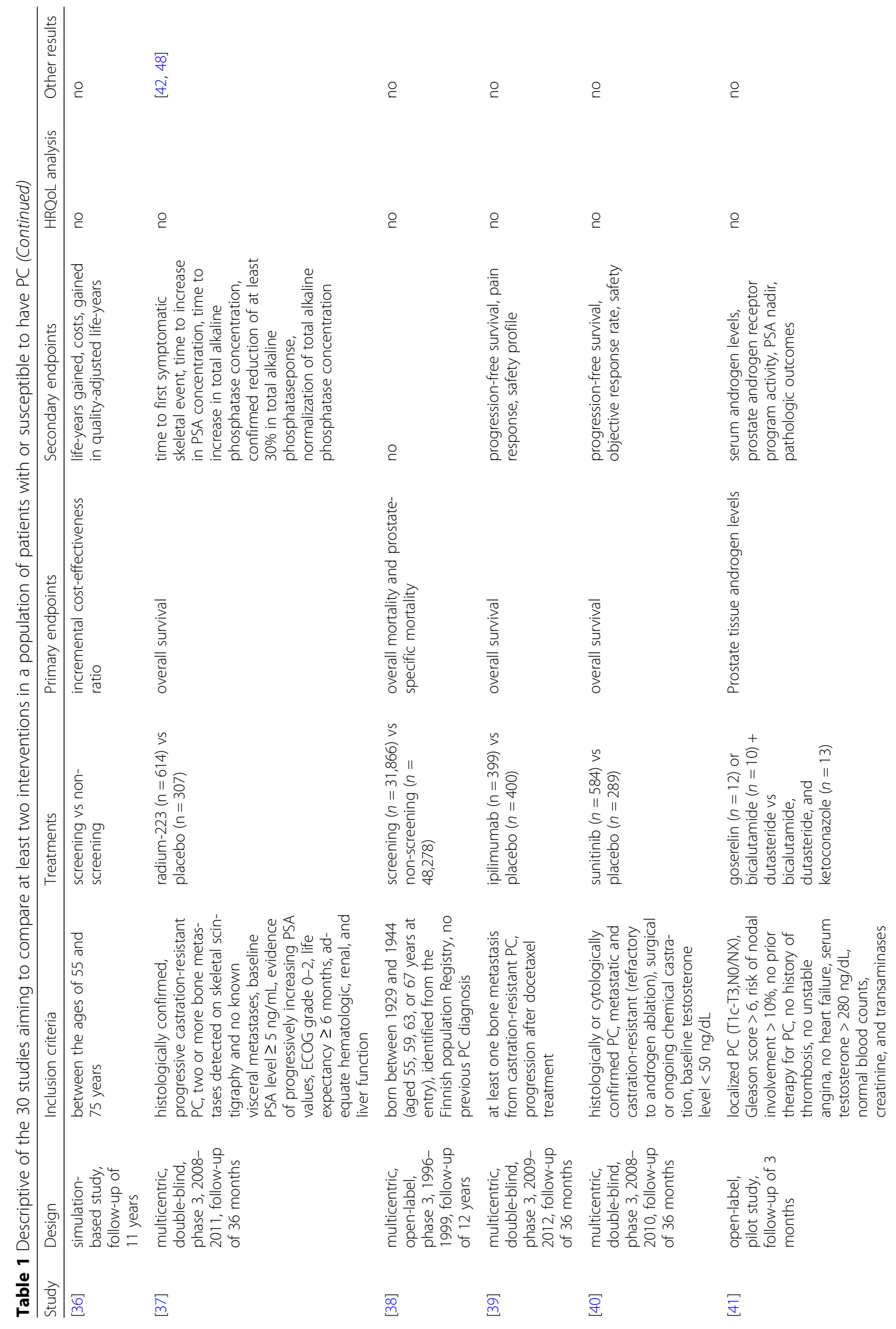




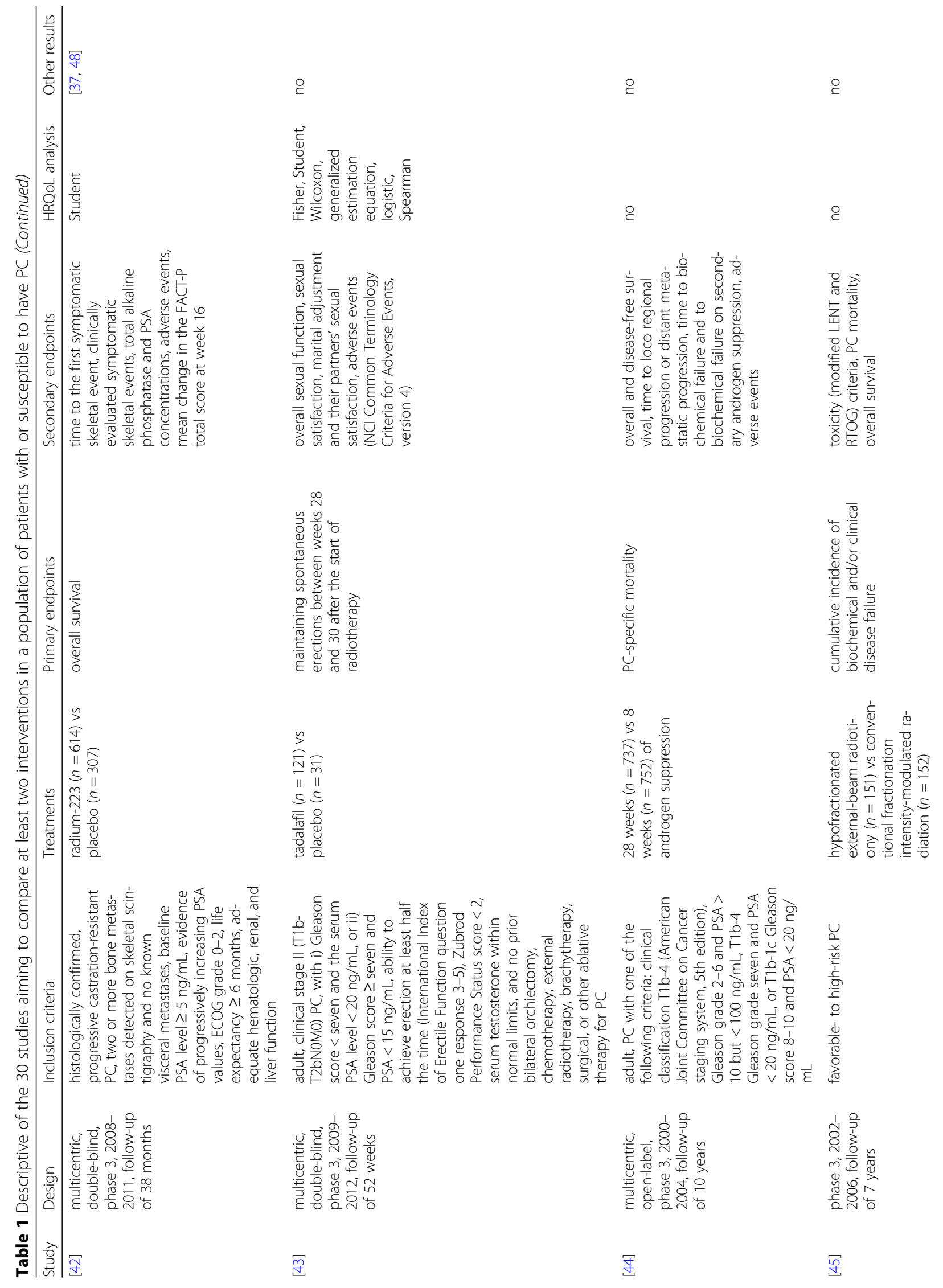




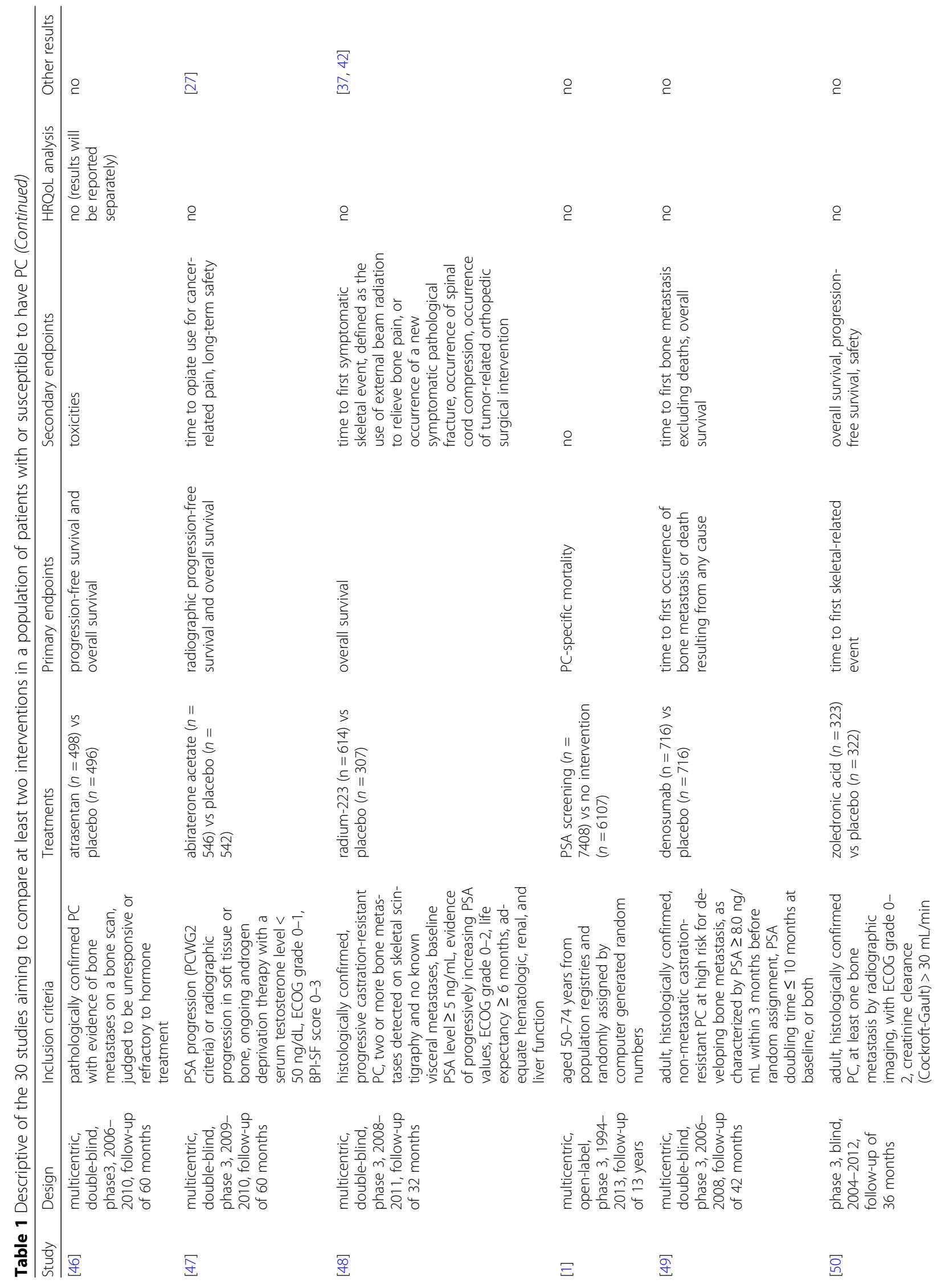




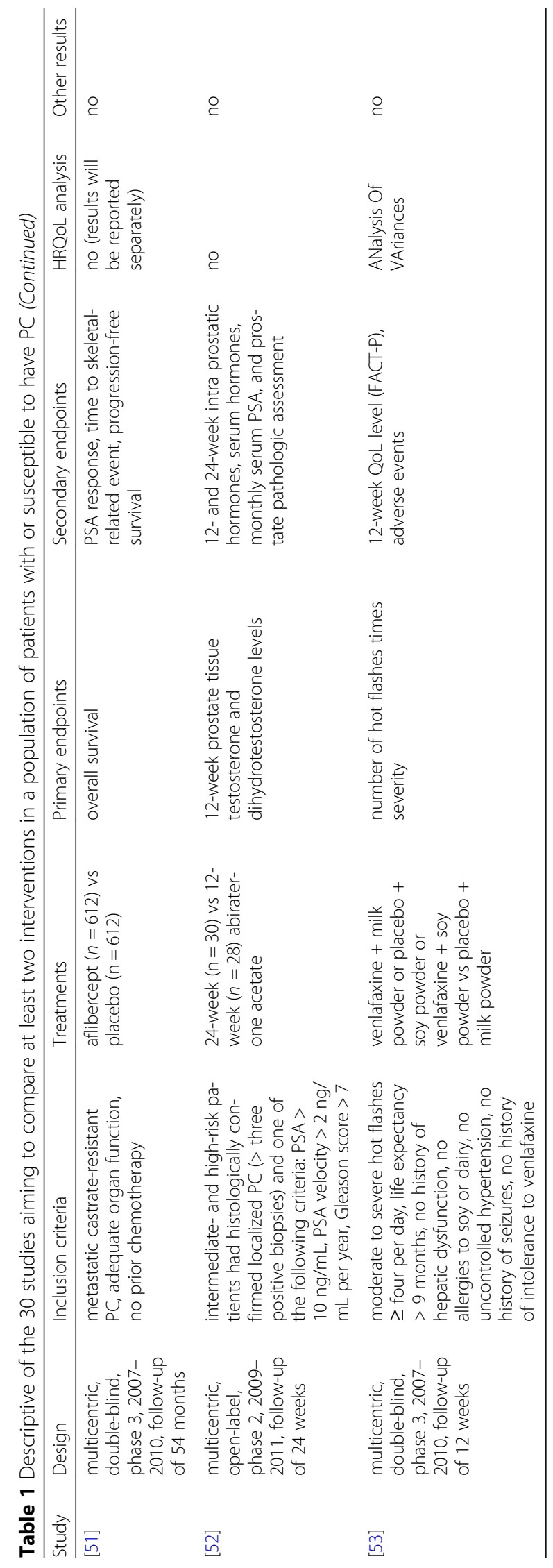


change, defined as a relative change from baseline higher than a given percentage, or ii) the absolute difference between the HRQoL means at baseline and at a given post-baseline time.

More precisely, the time to HRQoL change was explored in four papers [27, 28, 33, 35]. The statistical analyses were based on the Kaplan-Meier estimator associated with the Log-Rank test or the Cox model. The definitions considered for the time to HRQoL change were heterogeneous:

- In the study by Basch et al. [27], the authors studied the time from baseline to: a 10-point decrease of the FACT-P total score, or a 9-point decrease of the FACT-G score, or a 9-point decrease of the TOI.

- In the study by Beer et al. [28], the authors studied the time from baseline to a 9-point decrease of the FACT-P total score.

- In the study by Fizazi et al. [33], the authors studied two different endpoints: i) the time to deterioration of symptoms in the FAPSI, and ii) the time to deterioration of HRQoL in the FACT-P total score. In the two cases, there was no precision on the used threshold.

- In the study by Fizazi et al. [35], the authors studied the time from baseline to a 10-point decrease of the FACT-P total score or death from any cause, whichever occurred first. Note that the authors compared additional HRQoL endpoints, but without taking into account the time-dependent characteristic of the HRQoL: the percentage of patients with at least a 10-point improvement in the FACT-P total score at any post-baseline assessment and the percentages of patients with at least a 3-point improvement in the five FACT-P subscales (physical wellbeing, social or family wellbeing, emotional wellbeing, functional wellbeing, and PCS). The six percentages were compared by using the stratified Cochran-Mantel-Haenszel test.

In the two remaining studies using the FACT-P, Parker et al. [42] compared the mean change in the FACT-P total score from baseline to week 16 (Student t-test), while Vitolins et al. [53] compared the 12-week HRQoL level by considering six different endpoints (ANalysis Of Variance): the FACT-P total score, the FACT-G score, the social wellbeing, the physical wellbeing, the emotional wellbeing, the functional wellbeing and the PCS.

Interestingly, one can notice that the 8 papers partially based on the PRO collection [26-28, 33, 35, 42, 43, 53] were differentially distributed according to the curative/palliative treatments. Among the 12 papers related to curative treatments, only 1 paper (8.3\%) collected PRO [43]. In contrast, among the 18 papers related to palliative treatments, 7 papers (38.9\%) collected PRO [26-28, 33, 35, 42, 53].

\section{Merging the survival and the $\mathrm{HRQ}$ oL dimensions}

All papers analyzed these two dimensions separately, except for two papers [35, 36]. In the study by Fizazi et al. [35], the time to the first event between the HRQoL decrease and the patient death was studied. Heijnsdijk et al. [36] were interested in Quality-Adjusted Life-Years (QALYs) for merging the information about survival and HRQoL in order to perform a cost-effectiveness analysis of PC screening. Nevertheless, in their study, the HRQoL was not individually collected: assumptions were made regarding other data published in the literature.

\section{Discussion}

In the treatment of $\mathrm{PC}$, the most effective intervention in terms of survival may not necessarily be the best one from the patient's perspective if survival gain involves serious HRQoL deterioration due to treatments sideeffects on sexual, urinary and bowel functions. Thus, in randomized clinical trials, it appears important to describe trade-offs between survival and HRQoL. Following this line, the Food and Drug Administration (FDA) has published a guidance document promoting the inclusion of patient-reported outcomes measures in drug development [62]. Moreover, several steps have been identified and proposed for a more patient-centered approach to drug development [63,64], including patientcentered outcome research which aims to allow the voices of patients to be heard in assessing the value of health care options. In order to evaluate what is currently done in PC clinical research, we performed a mini-review focusing on randomized clinical trials published between 2013 and 2015 in medical journals with a high impact factor.

Among the 30 selected studies, only two papers attempted to merge the patient survival and HRQoL in a single endpoint. The first one, proposed by Fizazi et al. [35], compared the time to the first event between the patient death and the HRQoL deterioration. However, assuming death and HRQoL deterioration are equally important raises questions. The second one, proposed by Heijnsdijk et al. [36], computed QALYs to conduct a cost-effectiveness analysis of PC screening. Although QALYs have been primarily designed for economic evaluation purposes they could also prove useful for clinical decision making $[65,66]$. In the late 1990's the concept of Q-TWIST (Quality-adjusted Time WIthout Symptoms of disease and Toxicity of treatment), which is nearly identical to that of QALYs, has been used by physicians to present the results of PC clinical trials [67, 68]. Broadly speaking, QALYs are computed by assigning to the health states a synthetic HRQoL score, called "utility score", ranging from zero (death) to one (perfect health) so that each year of life is weighted by the corresponding utility score given the patient's health state. 
More precisely, 1 QALY represents 1 year alive in perfect health. For instance, a patient living 10 years with a utility at 0.8 will a have 8 QALYs $\left(10^{*} 0.8\right)$. This value would be lower for a patient living for 12 years but with an utility at 0.6, the number of QALYs would then be $7.2(12 \% 0.6)$ due to a more efficient intervention but with important side effects for example. But the main limitation of the study proposed by Heijnsdijk et al. [36] is that the utility scores used to calculate QALYs were not individually collected during the trial, but they were retrieved from literature.

Among the 30 selected papers, only six papers proposed HRQoL collection but as a secondary endpoint with a short-term follow-up. Two additional papers compared the interventions in terms of specific PRO. This low proportion of PRO-based papers $(8 / 30)$, is even more dramatic for curative treatments (1/12) compared to palliative treatments (7/18). The analyses of HRQoL were always performed separately from those related to patient survival. This way of presenting results did not allow an interpretation of the potential trade-offs between quantity and quality of life. The shortness of the follow-up in these studies also represents an important limit for balancing between the long-term quantity and quality of life. Moreover, even if six papers used the FACT-P questionnaire, the statistical analyses were highly heterogeneous. For instance, among the four papers in which the time from baseline to HRQoL change was described, the definitions of the HRQoL change were different, and the interval censoring and the informative censoring due to patient death were not taken into account in the analyses. As previously emphasized by Efficace et al. [69], who described that only onefifth of randomized clinical trials in PC reported adequately PRO data to draw meaningful conclusions, our results indicated that methodological improvements related to HRQoL analyses are essential for a better interpretation by physicians. For instance, Martin et al. [70] have recently provided useful guidelines for better standardizing patient-centered outcomes.

As a matter of fact, specific methodological issues related to PRO analysis do not seem to be considered nor discussed in most of the six PRO-based studies of our review, such as missing data management or choosing a threshold for minimal important change in HRQoL level. Indeed, information on missing data description and analysis is often lacking, which is unfortunate. Such data are likely to be missing not at random, which might lead to biased estimates of treatment effect. Moreover, the choice of thresholds for time to HRQoL change, is either unjustified or refers to the concept of Minimal Clinically Important Difference (MCID) proposed by Cella et al. [55] The latter constituted an important step but it has nevertheless to be outlined that a sample- dependent statistically-based approach was used, which did not rely on the patient's perspective.

In this mini-review, we voluntary restricted our study to trials published between 2013 and 2015 in medical journals with a high impact factor. This limits the generalizability of the findings. Firstly, we did not include the year 2016, while several important studies have been published. For instance, the ProtecT clinical trial aimed to compare active monitoring, radical prostatectomy, and external-beam radiotherapy for the treatment of clinically localized PC [71, 72]. The authors described separately, in two different papers, the clinical endpoints [71] and the patient-reported endpoints [72]. Again, this illustrates the need of developing future clinical trials that better consider the balance between quantity and quality of life in a single endpoint, such as QALYs. Secondly, many important studies are not published in these journals with high-impact. The researchers who publish in high-impact journals have distinct profiles compared with the researchers who publish in lowimpact journals [73], and the cancer trials with positive outcomes are more likely to be published in journals with high-impact [74]. Note also that all main urological journals were not included because of an impact factor lower than 15.

However, the limitations do not disqualify the central message of our mini-review. Our aim was not to propose a complete systematic review, but rather to illustrate the paradox between acknowledging that the treatment choice involves trade-offs between quality and quantity of life and the scarcity of studies that take them into account. Among the 30 selected studies with high-impact, no study precisely describes the potential trade-offs between quantity and quality of life. Based on this result, one can reasonably suggest to further consider composite patient-centered outcomes in future clinical trials, especially for those published in journals with high-impact. Future studies should also take into consideration some psychological aspects that may affect HRQoL $[75,76]$ and the important role of the family [77].

\section{Conclusion}

In conclusion, our mini-review suggests that recent clinical trials published in journals with high-impact are not designed to precisely describe the potential trade-offs between the quantity and the quality of life. It is now time to avoid designing trials that mainly, or even only, consider clinical efficacy. Composite patient-centered outcomes merging the quantity with the quality of life are needed to propose the most appropriate treatment on behalf of patients' best interest. We recommend the use of indicators such as QALYs as principal endpoint in future clinical trials. 


\section{Additional file}

Additional file 1: The research equation used in PubMed. (DOCX $16 \mathrm{~kb}$ )

Additional file 2: The Preferred Reporting Items for Systematic review and Meta-Analysis Protocols (PRISMA-P) checklist. (DOCX 16 kb)

\section{Abbreviations}

BPI-SF: Short Form of the Brief Pain Inventory; FACT-G: Functional Assessment of Cancer Therapy - General (any tumor type); FACTP: Functional assessment of cancer therapy for prostate cancer; FAPSI: FACT Advanced Prostate Symptom Index; HRQoL: Health-Related Quality of Life; MCID: Minimal clinically important difference; Mesh: Medical subject headings; PC: Prostate cancer; PCS: Prostate cancer subscale; TOI: Trial Outcome Index

\section{Acknowledgements}

Not applicable.

\section{Funding}

This work was supported by the Cancer National Institute (INCa, MAPMARKER, N²013-137).

\section{Availability of data and materials}

Data sharing not applicable to this article as no datasets were generated or analyzed during the current study.

\section{Authors' contributions}

All authors contributed to the design of this paper. YF searched the literature, conceived and designed the study. YF, ML and ED contributed to the data extraction. PT and VS contributed to the PRO data expertise. SS participated in the prostate cancer expertise. All authors critically revised the manuscript and approved the final version.

\section{Ethics approval and consent to participate}

Not applicable.

\section{Consent for publication}

Not applicable.

\section{Competing interests}

The authors declare that they have no competing interests.

\section{Publisher's Note}

Springer Nature remains neutral with regard to jurisdictional claims in published maps and institutional affiliations.

\section{Author details}

'SPHERE (MethodS for Patients-centered outcomes and HEalth Research), INSERM UMR 1246, Nantes University, IRS2 - 22 boulevard Bénoni Goullin, 44200 Nantes, France. ${ }^{2} \mathrm{CHU}$ Nantes University Hospital, Nantes, France. ${ }^{3}$ ICO - Institut de Cancérologie de l'Ouest - Centre René Gauducheau, Boulevard Jacques Monod, 44805 Saint-Herblain, France.

Received: 23 May 2017 Accepted: 26 February 2018

Published online: 05 March 2018

\section{References}

1. Schröder FH, Hugosson J, Roobol MJ, Tammela TLJ, Zappa M, Nelen V, et al. The European randomized study of screening for prostate cancer - prostate cancer mortality at 13 years of follow-up. Lancet. 2014;384:2027-35.

2. Bray F, Lortet-Tieulent J, Ferlay J, Forman D, Auvinen A. Prostate cancer incidence and mortality trends in 37 European countries: an overview. Eur J Cancer. 2010;46:3040-52

3. D'Amico AV, Whittington R, Malkowicz SB, Schultz D, Blank K, Broderick GA, et al. Biochemical outcome after radical prostatectomy, external beam radiation therapy, or interstitial radiation therapy for clinically localized prostate cancer. JAMA. 1998;280:969-74.

4. Cooperberg MR, Pasta DJ, Elkin EP, Litwin MS, Latini DM, Du Chane J, et al. The University of California, san Francisco cancer of the prostate risk assessment score: a straightforward and reliable preoperative predictor of disease recurrence after radical prostatectomy. J Urol. 2005;173:1938-42.

5. Chang AJ, Autio KA, Roach M, Scher HI. High-risk prostate cancerclassification and therapy. Nat Rev Clin Oncol. 2014;11:308-23.

6. Klotz L, Emberton M. Management of low risk prostate cancer-active surveillance and focal therapy. Nat Rev Clin Oncol. 2014;11:324-34.

7. Wilke DR, Krahn M, Tomlinson G, Bezjak A, Rutledge R, Warde P. Sex or survival: short-term versus long-term androgen deprivation in patients with locally advanced prostate cancer treated with radiotherapy. Cancer. 2010;116:1909-17.

8. Singer PA, Tasch ES, Stocking C, Rubin S, Siegler M, Weichselbaum R. Sex or survival: trade-offs between quality and quantity of life. J Clin Oncol Off J Am Soc Clin Oncol. 1991;9:328-34.

9. Sculpher M, Bryan S, Fry P, de Winter P, Payne H, Emberton M. Patients' preferences for the management of non-metastatic prostate cancer: discrete choice experiment. BMJ. 2004:328:382.

10. King MT, Viney R, Smith DP, Hossain I, Street D, Savage E, et al. Survival gains needed to offset persistent adverse treatment effects in localised prostate cancer. Br J Cancer. 2012;106:638-45.

11. van Tol-Geerdink JJ, Willem Leer J, Weijerman PC, van Oort IM, Vergunst $H_{\text {, }}$ van Lin EN, et al. Choice between prostatectomy and radiotherapy when men are eligible for both: a randomized controlled trial of usual care vs decision aid. BJU Int. 2013;111:564-73.

12. Goineau $A$, d'Aillières $B$, de Decker $L$, Supiot $S$. Integrating geriatric assessment into decision-making after prostatectomy: adjuvant radiotherapy, salvage radiotherapy, or none? Front Oncol. 2015;5:227.

13. Martin JM, Supiot S, Berthold DR. Pharmacotherapeutic management of ocally advanced prostate cancer: current status. Drugs. 2011;71:1019-41.

14. Goldkorn A, Ely B, Quinn DI, Tangen CM, Fink LM, Xu T, et al. Circulating tumor cell counts are prognostic of overall survival in SWOG S0421: a phase III trial of docetaxel with or without atrasentan for metastatic castration-resistant prostate cancer. J Clin Oncol Off J Am Soc Clin Oncol. 2014:32:1136-42.

15. Halabi S, Lin C-Y, Small EJ, Armstrong AJ, Kaplan EB, Petrylak D, et al. Prognostic model predicting metastatic castration-resistant prostate cancer survival in men treated with second-line chemotherapy. J Natl Cancer Inst. 2013:105:1729-37.

16. Halabi S, Armstrong AJ, Sartor O, de Bono J, Kaplan E, Lin C-Y, et al. Prostate-specific antigen changes as surrogate for overall survival in men with metastatic castration-resistant prostate cancer treated with second-line chemotherapy. J Clin Oncol Off J Am Soc Clin Oncol. 2013:31:3944-50.

17. Park K, Dalton JT, Narayanan R, Barbieri CE, Hancock ML, Bostwick DG, et al. TMPRSS2:ERG gene fusion predicts subsequent detection of prostate cancer in patients with high-grade prostatic intraepithelial neoplasia. J Clin Oncol Off J Am Soc Clin Oncol. 2014;32:206-11.

18. Lara PN, Ely B, Quinn DI, Mack PC, Tangen C, Gertz E, et al. Serum biomarkers of bone metabolism in castration-resistant prostate cancer patients with skeletal metastases: results from SWOG 0421. J Natl Cancer Inst. 2014;106:dju013.

19. Ryan CJ, Molina A, Li J, Kheoh T, Small EJ, Haqq CM, et al. Serum androgens as prognostic biomarkers in castration-resistant prostate cancer: results from an analysis of a randomized phase III trial. J Clin Oncol Off J Am Soc Clin Oncol. 2013;31:2791-8.

20. Kitahara CM, Berndt SI, de González AB, Coleman HG, Schoen RE, Hayes RB, et al. Prospective investigation of body mass index, colorectal adenoma, and colorectal cancer in the prostate, lung, colorectal, and ovarian cancer screening trial. J Clin Oncol Off J Am Soc Clin Oncol. 2013;31:2450-9.

21. Lane JA, Donovan JL, Davis M, Walsh E, Dedman D, Down L, et al. Active monitoring, radical prostatectomy, or radiotherapy for localised prostate cancer: study design and diagnostic and baseline results of the ProtecT randomised phase 3 trial. Lancet Oncol. 2014;15:1109-18.

22. Bagcchi S. PSA testing beneficial for prostate cancer. Lancet Oncol. 2014;15:e424

23. Brasky TM, Darke AK, Song X, Tangen CM, Goodman PJ, Thompson IM, et al. Plasma phospholipid fatty acids and prostate cancer risk in the SELECT trial. J Natl Cancer Inst. 2013:105:1132-41.

24. Sternberg CN, Castellano D, Daugaard G, Géczi L, Hotte SJ, Mainwaring PN, et al. Abiraterone acetate for patients with metastatic castration-resistant prostate cancer progressing after chemotherapy: final analysis of a multicentre, openlabel, early-access protocol trial. Lancet Oncol, 2014:15:1263-8.

25. Wei JT, Feng Z, Partin AW, Brown E, Thompson I, Sokoll L, et al. Can urinary PCA3 supplement PSA in the early detection of prostate cancer? J Clin Oncol Off J Am Soc Clin Oncol. 2014;32:4066-72. 
26. Araujo JC, Trudel GC, Saad F, Armstrong AJ, Yu EY, Bellmunt J, et al. Docetaxel and dasatinib or placebo in men with metastatic castrationresistant prostate cancer (READY): a randomised, double-blind phase 3 trial. Lancet Oncol. 2013;14:1307-16.

27. Basch E, Autio K, Ryan CJ, Mulders P, Shore N, Kheoh T, et al. Abiraterone acetate plus prednisone versus prednisone alone in chemotherapy-naive men with metastatic castration-resistant prostate cancer: patient-reported outcome results of a randomised phase 3 trial. Lancet Oncol. 2013;14:1193-9.

28. Beer TM, Armstrong AJ, Rathkopf DE, Loriot Y, Sternberg CN, Higano CS, et al. Enzalutamide in metastatic prostate cancer before chemotherapy. N Engl J Med. 2014;371:424-33.

29. Bill-Axelson A, Holmberg L, Garmo H, Rider JR, Taari K, Busch C, et al. Radical prostatectomy or watchful waiting in early prostate cancer. N Engl J Med. 2014:370:932-42.

30. Bosland MC, Kato I, Zeleniuch-Jacquotte A, Schmoll J, Enk Rueter E, Melamed J, et al. Effect of soy protein isolate supplementation on biochemical recurrence of prostate cancer after radical prostatectomy: a randomized trial. JAMA. 2013;310:170-8.

31. Dearnaley DP, Jovic G, Syndikus I, Khoo V, Cowan RA, Graham JD, et al. Escalated-dose versus control-dose conformal radiotherapy for prostate cancer: long-term results from the MRC RT01 randomised controlled trial. Lancet Oncol. 2014;15:464-73.

32. Denham JW, Joseph D, Lamb DS, Spry NA, Duchesne G, Matthews J, et al. Short-term androgen suppression and radiotherapy versus intermediate-term androgen suppression and radiotherapy, with or without zoledronic acid, in men with locally advanced prostate cancer (TROG 03.04 RADAR): an open-label, randomised, phase 3 factorial trial. Lancet Oncol. 2014;15:1076-89.

33. Fizazi K, Fizazi KS, Higano CS, Nelson JB, Gleave M, Miller K, et al. Phase III, randomized, placebo-controlled study of docetaxel in combination with zibotentan in patients with metastatic castration-resistant prostate cancer. J Clin Oncol Off J Am Soc Clin Oncol. 2013;31:1740-7.

34. Fizazi $K$, Massard $C$, Bono $P$, Jones $R$, Kataja $V$, James $N$, et al. Activity and safety of ODM-201 in patients with progressive metastatic castration-resistant prostate cancer (ARADES): an open-label phase 1 dose-escalation and randomised phase 2 dose expansion trial. Lancet Oncol. 2014;15:975-85.

35. Fizazi K, Scher HI, Miller K, Basch E, Sternberg CN, Cella D, et al. Effect of enzalutamide on time to first skeletal-related event, pain, and quality of life in men with castration-resistant prostate cancer: results from the randomised, phase 3 AFFIRM trial. Lancet Oncol. 2014;15:1147-56.

36. Heijnsdijk EA, de Carvalho TM, Auvinen A, Zappa M, Nelen V, Kwiatkowski $M$, et al. Cost-effectiveness of prostate cancer screening: a simulation study based on ERSPC data. J Natl Cancer Inst. 2015;107:366.

37. Hoskin P, Sartor O, O'Sullivan JM, Johannessen DC, Helle SI, Logue J, et al. Efficacy and safety of radium-223 dichloride in patients with castration-resistant prostate cancer and symptomatic bone metastases, with or without previous docetaxel use: a prespecified subgroup analysis from the randomised, double-blind, phase 3 ALSYMPCA trial. Lancet Oncol. 2014;15:1397-406.

38. Kilpeläinen TP, Tammela TL, Malila N, Hakama M, Santti H, Määttänen L, et al. Prostate cancer mortality in the Finnish randomized screening trial. J Natl Cancer Inst. 2013;105:719-25.

39. Kwon ED, Drake CG, Scher HI, Fizazi K, Bossi A, van den Eertwegh AJM, et al. Ipilimumab versus placebo after radiotherapy in patients with metastatic castration-resistant prostate cancer that had progressed after docetaxel chemotherapy (CA184-043): a multicentre, randomised, double-blind, phase 3 trial. Lancet Oncol. 2014;15:700-12.

40. Michaelson MD, Oudard S, Ou Y-C, Sengeløv L, Saad F, Houede N, et al. Randomized, placebo-controlled, phase III trial of sunitinib plus prednisone versus prednisone alone in progressive, metastatic, castration-resistant prostate cancer. J Clin Oncol Off J Am Soc Clin Oncol. 2014;32:76-82.

41. Mostaghel EA, Nelson PS, Lange P, Lin DW, Taplin ME, Balk S, et al. Targeted androgen pathway suppression in localized prostate cancer: a pilot study. J Clin Oncol Off J Am Soc Clin Oncol. 2014;32:229-37.

42. Parker C, Nilsson S, Heinrich D, Helle SI, O'Sullivan JM, Fosså SD, et al. Alpha emitter radium-223 and survival in metastatic prostate cancer. N Engl J Med. 2013;369:213-23.

43. Pisansky TM, Pugh SL, Greenberg RE, Pervez N, Reed DR, Rosenthal SA, et al. Tadalafil for prevention of erectile dysfunction after radiotherapy for prostate cancer: the radiation therapy oncology group [0831] randomized clinical trial. JAMA. 2014;311:1300-7.

44. Pisansky TM, Hunt D, Gomella LG, Amin MB, Balogh AG, Chinn DM, et al. Duration of androgen suppression before radiotherapy for localized prostate cancer: radiation therapy oncology group randomized clinical trial 9910. J Clin Oncol Off J Am Soc Clin Oncol. 2015;33:332-9.

45. Pollack A, Walker G, Horwitz EM, Price R, Feigenberg S, Konski AA, et al. Randomized trial of hypofractionated external-beam radiotherapy for prostate cancer. J Clin Oncol Off J Am Soc Clin Oncol. 2013;31:3860-8.

46. Quinn DI, Tangen CM, Hussain M, Lara PN, Goldkorn A, Moinpour CM, et al. Docetaxel and atrasentan versus docetaxel and placebo for men with advanced castration-resistant prostate cancer (SWOG S0421): a randomised phase 3 trial. Lancet Oncol. 2013;14:893-900.

47. Ryan CJ, Smith MR, Fizazi K, Saad F, Mulders PFA, Sternberg CN, et al. Abiraterone acetate plus prednisone versus placebo plus prednisone in chemotherapy-naive men with metastatic castration-resistant prostate cancer (COU-AA-302): final overall survival analysis of a randomised, doubleblind, placebo-controlled phase 3 study. Lancet Oncol. 2015;16:152-60.

48. Sartor O, Coleman R, Nilsson S, Heinrich D, Helle SI, O'Sullivan JM, et al. Effect of radium-223 dichloride on symptomatic skeletal events in patients with castration-resistant prostate cancer and bone metastases: results from a phase 3, double-blind, randomised trial. Lancet Oncol. 2014;15:738-46.

49. Smith MR, Saad F, Oudard S, Shore N, Fizazi K, Sieber P, et al. Denosumab and bone metastasis-free survival in men with nonmetastatic castration-resistant prostate cancer: exploratory analyses by baseline prostate-specific antigen doubling time. J Clin Oncol Off J Am Soc Clin Oncol. 2013;31:3800-6.

50. Smith MR, Halabi S, Ryan CJ, Hussain A, Vogelzang N, Stadler W, et al. Randomized controlled trial of early zoledronic acid in men with castrationsensitive prostate cancer and bone metastases: results of CALGB 90202 (alliance). J Clin Oncol Off J Am Soc Clin Oncol. 2014;32:1143-50.

51. Tannock IF, Fizazi K, Ivanov S, Karlsson CT, Fléchon A, Skoneczna I, et al. Aflibercept versus placebo in combination with docetaxel and prednisone for treatment of men with metastatic castration-resistant prostate cancer (VENICE): a phase 3, double-blind randomised trial. Lancet Oncol. 2013;14:760-8.

52. Taplin M-E, Montgomery B, Logothetis CJ, Bubley GJ, Richie JP, Dalkin BL, et al. Intense androgen-deprivation therapy with abiraterone acetate plus leuprolide acetate in patients with localized high-risk prostate cancer: results of a randomized phase II neoadjuvant study. J Clin Oncol Off J Am Soc Clin Oncol. 2014:32:3705-15.

53. Vitolins MZ, Griffin L, Tomlinson WV, Vuky J, Adams PT, Moose D, et al. Randomized trial to assess the impact of venlafaxine and soy protein on hot flashes and quality of life in men with prostate cancer. J Clin Oncol Off J Am Soc Clin Oncol. 2013;31:4092-8.

54. Fizazi K, Jones R, Oudard S, Efstathiou E, Saad F, Wit R. De, et al. phase III, randomized, double-blind, multicenter trial comparing Orteronel (TAK-700) plus prednisone with placebo plus prednisone in patients with metastatic castration-resistant prostate cancer that has progressed during or after docetaxel-based therapy: ELM-PC 5. J Clin Oncol. 2015;33:723-31.

55. Cella D, Nichol MB, Eton D, Nelson JB, Mulani P. Estimating clinically meaningful changes for the functional assessment of cancer therapy-prostate: results from a clinical trial of patients with metastatic hormone-refractory prostate cancer. Value Health J Int Soc Pharmacoeconomics Outcomes Res. 2009;12:124-9.

56. Victorson DE, Beaumont JL, Rosenbloom SK, Shevrin D, Cella D. Efficient assessment of the most important symptoms in advanced prostate cancer: the NCCN/FACT-P symptom index. Psychooncology. 2011;20:977-83.

57. Daut RL, Cleeland CS, Flanery RC. Development of the Wisconsin brief pain questionnaire to assess pain in cancer and other diseases. Pain. 1983;17:197-210.

58. Cleeland CS. The measurement of pain from metastatic bone disease: capturing the patient's experience. Clin Cancer Res Off J Am Assoc Cancer Res. 2006;12:6236s-42s.

59. Porst H, Vardi Y, Akkus E, Melman A, Park NC, Seftel AD, et al. Standards for clinical trials in male sexual dysfunctions. J Sex Med. 2010;7:414-44.

60. Waterhouse J, Metcalfe MC. Development of the sexual adjustment questionnaire. Oncol Nurs Forum. 1986;13:53-9.

61. Kimmel D, van der Veer F. Factors of marital adjustment in Locke's marital adjustment test. J Marital Fam Ther. 1974;36:57-62.

62. Silver Spring, MD: Food and Drug Administration. Guidance for industry patient-reported outcomes measures: use in medical product development to support labeling claims. 2009. Available from: http://www.fda.gov/ 
downloads/Drugs/GuidanceComplianceRegulatoryInformation/Guidances/ UCM193282.pdf. Accessed 02 Mar 2018.

63. Methodology Committee of the Patient-Centered Outcomes Research Institute (PCORI). Methodological standards and patient-centeredness in comparative effectiveness research: the PCORI perspective. JAMA. 2012;307:1636-40.

64. Basch E. Toward patient-centered drug development in oncology. N Engl J Med. 2013;369:397-400.

65. Kind P, Lafata JE, Matuszewski K, Raisch D. The use of QALYs in clinical and patient decision-making: issues and prospects. Value Health J. Int. Soc. Pharmacoeconomics Outcomes Res. 2009;12(Suppl 1):S27-30.

66. Sloan JA, Sargent DJ, Novotny PJ, Decker PA, Marks RS, Nelson H. Calibration of quality-adjusted life years for oncology clinical trials. J Pain Symptom Manag. 2014;47:1091-1099.e3.

67. Pummer K, Lehnert M, Stettner H, Hubmer G. Randomized comparison of total androgen blockade alone versus combined with weekly epirubicin in advanced prostate cancer. Eur Urol. 1997;32(Suppl 3):81-5.

68. Rosendahl I, Kiebert GM, Curran D, Cole BF, Weeks JC, Denis LJ, et al. Quality-adjusted survival (Q-TWiST) analysis of EORTC trial 30853: comparing goserelin acetate and flutamide with bilateral orchiectomy in patients with metastatic prostate cancer. European Organization for Research and Treatment of cancer. Prostate. 1999;38:100-9.

69. Efficace F, Feuerstein M, Fayers P, Cafaro V, Eastham J, Pusic A, et al. Patientreported outcomes in randomised controlled trials of prostate cancer: methodological quality and impact on clinical decision making. Eur Urol. 2014;66:416-27.

70. Martin NE, Massey L, Stowell C, Bangma C, Briganti A, Bill-Axelson A, et al. Defining a standard set of patient-centered outcomes for men with localized prostate cancer. Eur Urol. 2015;67:460-7.

71. Hamdy FC, Donovan JL, Lane JA, Mason M, Metcalfe C, Holding P, et al. 10year outcomes after monitoring, surgery, or radiotherapy for localized prostate cancer. N Engl J Med. 2016;375:1415-24.

72. Donovan JL, Hamdy FC, Lane JA, Mason M, Metcalfe C, Walsh E, et al. Patient-reported outcomes after monitoring, surgery, or radiotherapy for prostate cancer. N Engl J Med. 2016;375:1425-37.

73. Paiva CE, Araujo RLC, Paiva BSR, de Pádua SC, Cárcano FM, Costa MM, et al. What are the personal and professional characteristics that distinguish the researchers who publish in high- and low-impact journals? A multi-national web-based survey. Ecancermedicalscience. 2017;11 [cited 2017 Oct 3]; Available from: https://www.ncbi.nlm.nih.gov/pmc/articles/PMC5295845/

74. Tang P, Pond GR, Welch S, Chen EX. Factors associated with publication of randomized phase iii cancer trials in journals with a high impact factor. Curr Oncol. 2014;21:564-72.

75. Calia R, Lai C, Aceto P, Luciani M, Camardese G, Lai S, et al. Attachment style predict compliance, quality of life and renal function in adult patients after kidney transplant: preliminary results. Ren Fail. 2015;37:678-80.

76. Calia R, Lai C, Aceto P, Luciani M, Camardese G, Lai S, et al. Emotional selfefficacy and alexithymia may affect compliance, renal function and quality of life in kidney transplant recipients: results from a preliminary crosssectional study. Physiol Behav. 2015;142:152-4.

77. Lai C, Borrelli B, Ciurluini P, Aceto P. Sharing information about cancer with one's family is associated with improved quality of life. Psychooncology. 2017;26:1569-75.

\section{Submit your next manuscript to BioMed Central and we will help you at every step:}

- We accept pre-submission inquiries

- Our selector tool helps you to find the most relevant journal

- We provide round the clock customer support

- Convenient online submission

- Thorough peer review

- Inclusion in PubMed and all major indexing services

- Maximum visibility for your research

Submit your manuscript at www.biomedcentral.com/submit

) Biomed Central 